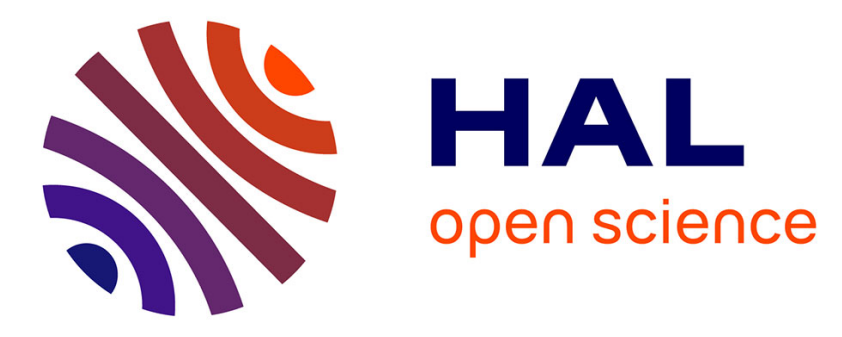

\title{
Coastal inconsistencies: Living with and anticipating coastal flood risks in southern France
}

\author{
Raquel Bertoldo, Séverin Guignard, Pierre Dias, Alexandra \\ Schleyer-Lindenmann
}

\section{- To cite this version:}

Raquel Bertoldo, Séverin Guignard, Pierre Dias, Alexandra Schleyer-Lindenmann. Coastal inconsistencies: Living with and anticipating coastal flood risks in southern France. International Journal of Disaster Risk Reduction, 2021, 64, pp.102521. 10.1016/j.ijdrr.2021.102521 . hal-03326488

\section{HAL Id: hal-03326488 \\ https://hal.science/hal-03326488}

Submitted on 26 Aug 2021

HAL is a multi-disciplinary open access archive for the deposit and dissemination of scientific research documents, whether they are published or not. The documents may come from teaching and research institutions in France or abroad, or from public or private research centers.
L'archive ouverte pluridisciplinaire HAL, est destinée au dépôt et à la diffusion de documents scientifiques de niveau recherche, publiés ou non, émanant des établissements d'enseignement et de recherche français ou étrangers, des laboratoires publics ou privés. 
Coastal inconsistencies: Living with and anticipating coastal flood risks in southern

France

Raquel Bertoldo

Aix Marseille Univ, LPS, Aix-en-Provence, France

\section{Séverin Guignard}

Pierre Dias

Alexandra Schleyer-Lindenmann

Aix Marseille Univ, Université Côte d'Azur, Avignon Université, CNRS, ESPACE, UMR 7300, Avignon, France

\section{Acknowledgements}

This work is a contribution to Labex OT-Med ( ${ }^{\circ}$ ANR-11-LABX-0061) and received funding from Excellence Initiative of Aix-Marseille University-A*MIDEX, a French “Investissements d'Avenir" programme (RISKMED project). Additional funding was provided for the study in France by the European Union-FEDER programme (DIGUE 2020 project). We would also like to thank Claire Mays for carefully reviweing a first version of this manuscript.

Corresponding author: Raquel Bertoldo. Laboratoire de Psychologie Sociale (UR 849), AixMarseille Université, 29 avenue Robert Schuman, 13621 Aix-en-Provence, France. Email: raquel.bohn-bertoldo@univ-amu.fr 


\begin{abstract}
As coastal floods will grow stronger due to climate change, coastal communities' capacity to perceive, understand and adapt to an evolving environment must be assessed. This study explores how inhabitants of two Mediterranean French cities, Fréjus and Port-Saint-Louis-duRhône (PSLR), understand and prepare for coastal flood risk. A constructivist approach was adopted combining elements of the Theory of Social Representations and the Social Amplification of Risk Framework. Semi-structured interviews were conducted with 41 inhabitants of these two localities. Local dwellers of the two cities base their knowledge of coastal flood risk on previous fluvial flood experiences. Affective attachment to the coast is expressed differently between localities - PSLR inhabitants describe an environmental history that is part of their personal history; whereas Fréjus inhabitants have elected this place to live. Risk attenuation argumentative strategies are identified: social comparison, risk comparison and fatalism. A shared understanding that 'something must happen' before coastal floods are taken seriously was also identified. This is discussed as an example of how the objectification process of social representations contributes to raising the societal awareness of new risks, or to their social amplification.
\end{abstract}

Keywords: coastal floods, floods, social representations, climate change adaptation, risk perception, SARF, place attachment. 
Communities dwelling by the coast have built over generations an understanding of how their local environment works (Bourrelier, Deneufbourg \& de Vanssay, 2000; Delicado, Guerreiro, \& Gomes, 2012). Climate change however may produce new weather and risk patterns (IPCC, 2018), whose impacts could push the limits of local knowledge to the point where communities must learn, again, how to adapt to local natural risks. In particular, coastal storms and resulting inundation may constitute an increasingly present threat to life and property - and community overall (Freedman, Dennis \& Karklis, 2020).

Recurring natural catastrophes and the gradual increase in human vulnerabilities have contributed to the development of institutional frameworks that organise the State response in matters of natural risks (c.f. Bourrelier, de Vanssay \& Deneufbourg, 2000). However, the experience of constant exposure to threatening environmental elements can also contribute to the 'normalization' of natural risks (Luís et al., 2016) as a mechanism to maintain positive emotional bonds to a place (Bonaiuto, Alves, De Dominicis, \& Petruccelli, 2016; Krien \& Michel-Guillou, 2014). Flood risk experience in this way has been associated with both support and resistance to flood risk adaptation measures.

This article presents a qualitative analysis in the goal of unpacking the contradictions involved in how communities make sense of and prepare for coastal flood events. Two southern French localities exposed to coastal floods risk were selected for this analysis: Port-Saint-Louisdu-Rhône, a small city at sea level, isolated in a wetland zone; and Fréjus, a mid-sized city of the Côte d'Azur with a booming real estate market for newly retired people.

This analysis adopts a constructivist approach to explore how local communities live with coastal flood risk and how they integrate scientific or technical concepts and predictions into locally shared meanings, or social representations (Moscovici, 2001). We examine as well the relationships built with propositions shared among risk managers and scientists but which fail to find an echo in the experience of local communities and thus remain abstract in regard to 
local practices (Harré, 1998; Castro \& Batel, 2008). Because these abstract specialist ideas are nonetheless recognised and valued elsewhere, a process of rationalisation arises that must also make sense in the context of how these communities view themselves, i.e. their social identities (Breakwell, 2001).

The mismatch between expert predictions of increasingly strong climate phenomena and impacts and the existing local experiences of coastal floods with local risk preparedness practices will here be analysed as local social knowledge that evolves as part of a local community project (Bauer \& Gaskell, 2008). We present a social representations approach (Moscovici, 2001) combined with a risk analysis approach opening a longitudinal perspective on social knowledge: the Social Amplification of Risk Framework (SARF) (Kasperson et al., 2003). Key overlapping elements will be illustrated by the empirical study. Combining elements from these two theoretical perspectives allows a better understanding of how these evolving natural risks, which exist in the scientific and policy spheres, are not yet 'seen' (Moscovici, 1984) by the local communities that will be the most exposed to them.

\section{Living with long 'known' risks: Social representations and coastal risks}

Attempts to make the public aware of a risk are common in the risk management policy field (Renn, 2008). They may root in a 'deficit model' where the public is regarded as naïve in the face of an environment that holds secrets that are better known by specialists (Wynne, 1996). Nonetheless, traditional communities over generations have elaborated and mastered locally meaningful adaptation strategies based on careful environmental observations (Nazarea, 2006).

The social representations approach describes how new knowledge emanating mainly (but not exclusively) from scientific spheres is appropriated across different social groups and integrates shared meanings, or representations (Moscovici, 1976, 1984, 2001). This diffusion process involves the sharing of new information and also produces new meanings in the process 
(Joffe, 2003): laypeople then resort to metaphors and images to translate these yet novel ideas into familiar ones. "The representations we fabricate - of a scientific theory, a nation, an artefact, etc. - are always the result of a constant effort to make usual and actual something which is unfamiliar or which gives us a feeling of unfamiliarity" (Moscovici, 1984, p. 27). Familiarity on the other hand depends on how memories are used to recognise social objects (anchor) and reify them (objectification). By anchoring new knowledge in older ones, social groups are comparing, classifying, and naming them. Moreover, the process of categorisation is not by any means neutral, since it "amounts to choosing a paradigm from those stored in our memory and establishing a positive or a negative relation with it" (Moscovici, 1984, p. 31). The twin process of objectification is that what gives 'reality' to new and otherwise abstract ideas. Therefore, when an image linked with a word or concept "is detached and is let loose in a society it is accepted as a reality, a conventional one, of course, but nonetheless a reality" (Moscovici, 1984, p. 39). By being objectified these new ideas "become expressions of a reality thought as natural" (Vala, 2000, p. 465, our translation). The two intrinsically related processes of anchoring and objectification new meanings have progressively changed the way the French coast is understood: as a place of leisure but also as a place of risk (Krien \& Michel-Guillou, 2014; Meur-Ferec \& Guillou, 2019).

Understanding social knowledge as meaning rather than as information is particularly important in the case of risk. The widespread concept of 'risk perception' often used in risk literature mainly refers to the individual processing of cognitive, and more recently emotional input in relation to risk (Joffe, 2003; Slovic, 2000). In our understanding, individually perceived risks are also socially constructed through shared ideas and representations that grant to these objects their reality value. "While perception is based upon sensorial knowledge, representation is concerned with symbols, social reality and social knowledge" (Joffe, 2003, p. 60). Because environmental events involve different sorts of information ranging from sensorial to symbolic, 
we here consider risk representation as an overarching shared knowledge structure that conveys to risk perception its meaning which might, under different circumstances, be amplified or made completely invisible (Joffe, 2003).

Studies have demonstrated that along the French Atlantic (Michel-Guillou, Lalanne, \& Krien, 2015; Michel-Guillou \& Meur-Ferec, 2017) and Mediterranean (Durand et al., 2018) coasts local inhabitants are aware of their exposure to coastal flooding yet unworried by the risk (Meur-Ferec \& Guillou, 2020; Michel-Guillou et al., 2016; Michel-Guillou et al., 2015). This has been described, from a strictly informational perspective, as a "poor risk culture" (Durand et al., 2018. p. 10). Other studies have interpreted this lack of local concern as a logical 'paradox' that finds its meaning in locally shared social representations; based on a series of studies in risk-prone coastal French communities Meur-Ferec and Guillou (2020) conclude that: (a) local people are aware of risks but are not worried; (b) local people are aware of risks and are still place-attached; and (c) local people are willing to act but resist government-proposed adaptation strategies. The first two points ( $a$ and $b$ ) are supported by the common observation that coastal communities are aware of coastal risks (Doue et al., 2020; Michel-Guillou et al., 2015; Michel-Guillou \& Meur-Ferec, 2017); but because of a strong attachment to socially and economically valued real estate by the sea these threats are downplayed (Bonaiuto et al., 2016; Michel-Guillou et al., 2016). The paradox (c) underlines a sort of felt threat posed by the enforcement of the PPRI (Plan de Prévention des Risques Inondation or 'Flood Risk Prevention Plan') that would, in the communities' perspective, limit real estate development or even lead to evictions. The development of risk management tools has accelerated local natural risk management (Bourrelier et al., 2000). Yet the success of these tools may be less visible than their failures, since the latter have much more disruptive consequences. Failed measures have in some local contexts been described as more anxiogenic than the coastal risks they are meant to address (Krien \& Michel-Guillou, 2014; Lelaurain et al., in revision). 


\section{Social Amplification of Risk Framework and coastal risks}

Coastal inhabitants have long been exposed to storm-like events in winter months, to the point where they may be regarded as not really dangerous (Michel-Guillou et al., 2015), or as natural events which they regard as 'normal' (Luís et al., 2016). Any impression that coastal communities are collectively adapted to coastal events was challenged in France by the 2010 Xynthia storm that killed 59 Atlantic residents of the Charente-Maritime and Vendée regions. Xynthia has been described as an 'unremarkable' (Chadenas et al., 2014) meteorological event aggravated by a rare conjunction of factors - atmospheric pressure, strength and orientation of the wind, tidal range. The strength of the coastal flood and its impact on the built environment of La Faute-sur-Mer and its inhabitants called into question the urbanisation strategies that allowed real estate development in a flood plain (Chadenas et al., 2014). While prior catastrophic fluvial floods - Nîmes (1988), Vaison-la-Romaine (1992) ou Arles (2003) - had prompted the elaboration of local risk prevention plans (Bourrelier et al., 2000), Xynthia called State attention to the dangers of coastal floods (Calvet \& Manable, 2015) and to how vulnerable coastal regions were to this category of natural risks only expected to increase with climate change (IPCC, 2018). From a Social Amplification of Risk Framework (SARF) point of view, coastal flood risk has, from that point on, been socially amplified (Kasperson et al., 1988).

SARF was initially proposed as an integrative approach in risk research that provides overarching explanations to how social, economic and psychological factors dynamically overlap and contribute to increasing or decreasing the perceptions of a hazard (Kasperson et al., 1988; Pidgeon, Kasperson \& Slovic, 2003). The SARF uses the metaphor of signal amplification from classical communications theory to explain how individuals, social groups and societies generate, attenuate or amplify risk 'signals'. In this sense, a hazard, or risk event will likely be ignored unless someone capable of interpreting it (1) 'sees' it and (2) 
communicates about it to others (Luhmann, 1979). Risk amplification is therefore proposed by this approach as an illustration of how communication stations intensify or attenuate "risk signals' over their successive transmission until they reach the final active receivers (Kasperson et al., 1988).

Still, Kasperson et al. (1988) among other critics (Bakir, 2005; Burgess, 2012) recall that the amplification metaphor is a simplified description that fails to take into account the fact that in modern societies "messages have a meaning for the receiver only within a sociocultural context" (Kasperson et al., 1988, p. 180, emphasis added). If we consider this sociocultural context as constituted by social representations, we might more clearly explain why some "amplification stations" - i.e. representational contexts characterised by an institution, community, social group - increase or amplify risk perception while others reduce or attenuate social risk perception. These 'stations' interpret information according to already available symbols and images, which leads to particular understandings and consecutive responses by other participants in the social system (Kasperson et al., 2003).

Considering therefore how the French society has responded to coastal risks in the past, studies suggest that "normalization" (Luís et al., 2016) or attenuating coping strategies (MeurFerec \& Guillou, 2020; Bourrelier et al., 2000) are common. It was also undeniable that the Xynthia storm played an important role in galvanising the public memory around an event that set a precedent for coastal risk management and preparedness (Chadenas et al., 2014). This storm event was important to amplify the societal response to coastal risks in general: the disruption it brought about locally allowed French society to attach meaning to the event and to prepare for increasingly strong storms (Calvet \& Manable, 2015).

\section{Coastal flood risk understandings: A qualitative analysis}


Communities dwelling in Mediterranean regions have integrated knowledge about their environment as part of locally relevant social practices (Delicado et al., 2012). Coastal storms are seen as a normal part of winter months (Luís et al., 2016). Yet climate change is already disrupting a previously familiar environment.

Considering the increasing strength of coastal floods due to climate change and the importance of local preparedness for coastal floods to mitigate potential hazard impacts (Poumadère et al., 2015), how do coastal French communities exposed to coastal flood risk make sense of such events, experienced, or anticipated? Which discourse do they use to justify local preparedness actions? Or is the hazard regarded as too small to warrant any type of risk preparedness? Previous studies have analysed these issues in the Atlantic coast - a region profoundly marked by the Xynthia storm and a number of strong coastal storms subsequently (Meur-Ferec \& Guillou, 2020; Michel-Guillou et al., 2016). We propose to analyse the discourse and logics around coastal floods around the Mediterranean coast, which has not yet experienced directly comparable storm damages but would nonetheless be greatly affected by climate change consequences (Cramer et al., 2018).

In order to respond to these questions two southern France communities were selected based on a similar exposure to coastal floods, but with different demographic profiles: PortSaint-Louis-du-Rhône (PSLR), a community adjacent to the routinely flooded Camargue plain; and Fréjus, a booming retirement destination on the Côte d'Azur. Qualitative semi-structured interviews (Smith, 1995) with 41 inhabitants of PSLR $(\mathrm{N}=20)$ and Fréjus $(\mathrm{N}=21)$ shed light on a rich nexus of experience, practice, logics and views present in the different communities.

\section{Method}

The study here described took place in two southern France localities on the Mediterranean coast: Port-Saint-Louis-du-Rhône and Fréjus. The fieldwork was conducted by 
two overlapping research consortia. The first, DIGUE2020, explores southern France anticipation of coastal floods and their relationship with marine dikes; the second, OT-Med RISKMED, compares naturally occurring risks in different Mediterranean countries - France (coastal floods), Italy (earthquake) and Morocco (floods and earthquakes) (Bertoldo et al., 2020; Ivcevic et al., 2020). These research operations have proposed similar research questions open enough to investigate and embrace the local cultures of risk. As mentioned above, we analyse this local appropriation of risk information as a social representations process (Moscovici, 1984). As such, this study was planned to elucidate and describe how an 'already known' environment becomes invested with 'new' information proposed by local bodies charged with risk management.

A common interview guide was developed for the international consortium, which was then adapted to the southern France issue of coastal flood. This interview guide covered a diversity of topics associated with coastal risk knowledge: local memory and experience of past natural events associated with coastal floods, knowledge of the phenomenon, trust in public risk management, protective behaviour, and place attachment. Considering our constructivist approach within social representations theory, local meaning making dynamics were assessed directly during the semi-structured interviews - points about knowledge, environmental observation, and information practices.

Fieldwork was initiated through a formal contact with the Town Hall of each city. Then local associations were contacted, and participants were subsequently recruited through snowballing until the saturation point was reached. Semi-directive interviews (Smith, 1995) were conducted in a variety of settings, depending on the convenience for the interviewee: in their residence, sometimes in public or semi-public places (association offices, workplaces, cafés, public parks, etc.). Each interview started with review of personal data protections and signature of an informed consent form (the project was approved by the committee for research 
ethics of the Aix-Marseille University). Interviews were audio recorded and fully transcribed average length was 45 minutes.

\section{Participants}

Twenty people were interviewed in Port-Saint-Louis, 13 of whom are men. Their average age is 58.8 years $(M=58.85 ; S D=14.59)$. Twenty-one participants were interviewed in Fréjus, 14 of whom are men. These participants are older on average $(M=65.6 ; S D=12.5)$.

\section{Analytical approach}

The fully transcribed interviews were then submitted to a content analysis (Flick, 2014). Considering our initial research question around coastal flood local understanding, some categories were already anticipated (e.g. emotional ties to the coast) while others were not (e.g. argumentative strategies). Therefore, this analysis combined top-down and bottom-up strategies. Most of the bottom-up content consists of what we call 'argumentative strategies' which are ideas that while being shared, have a pragmatic discursive function (Batel \& Castro, 2018). These argumentative strategies are here analysed as part of social representations as a phenomenon (Moscovici, 1984): “assuming - with TSR - that 'language users' are communicating in the context of self-other relations suggests paying attention also to power and asymmetries in those relations, and in the types of representations being used - so that we can understand whether they are resisting change or promoting it" (Batel \& Castro, 2018, p. 13). Therefore whereas these argumentative strategies might have an individual impact in terms of coping (Breakwell, 2001), they also have societal consequences when they are slowing down the implementation of risk adaptation measures.

We used a Computer-assisted Qualitative Data Analysis Software (CAQDAS) - Atlasti7 (Lewins \& Silver, 2007). This type of tool is used in qualitative analysis to organise and 
manage information. More precisely, Atlas-ti7 was used during the whole process of data analysis - transcript reading, interpreting, coding, and recoding. Content that provided responses - anticipated or not - to our research question was coded (Flick, 2014). The research team first read the full interview transcripts and agreed on a trial coding scheme (33 categories). During a second read some of these categories were combined or reorganised, leaving us with a total of 28 categories, organised around four meta-categories (Table 1): 'emotional ties to the coast', 'risk relativization', 'risk exposure description' and 'memories of past risk events'.

\section{*** Insert Table 1 about here ***}

The second author randomly selected a sample of a third of the interviews which were recoded with the same coding scheme. This procedure has the objective of assessing inter-coder reliability. After discussing specific disagreements, the first and second authors agreed in at least $90 \%$ of the cases - Krippendorff's alpha of .90 (Hayes and Krippendorff, 2007).

\section{Results}

Meta-categories presented in Table 1 above are analysed in detail below. Moreover, we will discuss how the socially shared content supports a hypothesis of coastal flood risk amplification or attenuation in our two study locales (PSLR and Fréjus).

\section{Knowledge of coastal flood risk exposure}

The risk knowledge category is presented first because we consider it to be an assessment of how local people understand their exposition to coastal flood risk in general as well as their sources of information on this subject. This content was present in greater length and detail in PSLR than in Fréjus - probably because of the fact that PSLR participants have resided there 
longer and tend to show more interest for their local environment (type of wind associated with sea waves, periods of flood risk, etc.).

It is important to note that both localities are beside river deltas - one of them, the Rhône delta delimiting the Camargue being the biggest delta in Europe. These environments are described, especially the Camargue (close to PSLR), as transition ecosystems that are exposed to both fluvial and marine flooding hazards. For this reason, when participants were asked about coastal floods, they often talked about fluvial floods instead. It became clear that based on their previous flood experiences these inhabitants are more concerned, and prepared, to deal with fluvial floods than they are with coastal floods. This passage illustrates this heightened concern for fluvial floods: "It's common to see people at 10 o'clock in the evening, [...] if the wind falls or rises, they will take a walk on the port of the [river] Rhône or on the locks, there are some specific points like that where they go take a look [...]. People take no interest in sea floods". Here inhabitants are seen to learn about their current risk exposure from previous experience and direct observation of their environment. Risks are described in detail through personal experience of hazard events. This type of first-hand knowledge illustrates their attention to subtle natural phenomena taking place in their territory.

Another example of discourse and images anchored in a fluvial imaginary is the term used by participants to describe coastal risks. The term specifically employed to describe the rise and flood of a river - 'crue de la rivière' - has been used to describe the invasion of sea water during a storm - or 'crue marine'. This example shows how previous collective memories are used to symbolically give meaning to another type of flood.

Participants' discourse about risk exposure also shows a familiarity with legal and technical aspects of flood risk in general (i.e. technical reports by the municipality, official risk characterizations, hydrology vocabulary, etc.). This demonstrates how these participants hybridize personal and technical knowledge when discussing their experience of risk exposure. 
In the following passage we can see how a participant integrates technical information in their own narrative of a risk experience: "since we understand very well that in periods like that of a centennial or millennial flood, the [Rhône] mouth is no longer enough. Water must come out [...] We filed detailed documents with the city technical services [...] at the time of the elaboration of the PLU [local urbanism plan]” (man, 58y, PSLR).

In both cities, inhabitants show a high degree of knowledge about their exposure to fluvial floods. They demonstrate both experiential (experience and observation) and formal (technical and legal) knowledge they hybridize in order to react to these coastal and fluvial floods. In the context of the delta, this knowledge is based on previous experience with river and runoff flood hazards. Coastal flood hazards do not seem to raise concerns in particular: they are often mentioned as part of wider hydrological phenomena involved in fluvial floods.

These qualitative findings illustrated how both localities share a 'flood' culture, mainly based on previous experiences of fluvial floods. These are the memories that raise concerns in the present and motivate locals to keep informed about their local environments. But is this specific risk knowledge enough to motivate protective action? In the next section we present how local dwellers think and act with the coast, a place their local history is intertwined with.

\section{Emotional ties to the coast}

Coastal areas are described as places abundant in natural resources. Today, the coast of Fréjus and PSLR is part of a way of life that involves proximity with nature and blue spaces. Described as pivotal in local practices and identities, these places also play an important emotional role. This emotional attachment to the seaside is felt in the way participants describe the coast past and present, and how they talk about risks.

Fréjus is described as a place surrounded by mountains, rivers and the seaside. Participants partly justify their choice of moving to Fréjus with the wealth of leisure 
opportunities around the city: sail, hiking, cycling, snorkelling and so on. Inhabitants mention feeling lucky to live in the Côte d'Azur - where real estate is rare and expensive - and consider the seaside as the jewel of their environment. The coast is therefore the source of positive emotions associated with leisure, not with negative emotions involved in perceived coastal risks.

In PSLR the risks presented by the coast and the Rhône are described in a romanticized way that mixes memories with nostalgia and local pride. This 'way of life' is well exemplified by the "cabanons" (cabana), small huts in the middle of the salt marsh that are cherished by PSLR inhabitants: "It's a real way of life and we are all equal when we meet there because there is no social class, there are people who have a lot of money who come to the cabana [...]. We are all the same, we are all in shorts, barefoot or in flip-flops and we eat the same thing, we invite each other, we respect each other, and we don't ask who we are" (woman, 65y, PSLR).

This way of life in close connection with nature can be described by the subsistence activities (fishing and hunting) and in the observation of natural cycles. For example, this person describes how they could base their subsistence entirely on local natural resources: "people are smarter now, but before, the old ones were tough because here you did not have to work to live. Everything was available in abundance [...] I tend to say that the Rhone is our god" (man, 70 $y, P S L R)$. The toughness this person mentions is also related to adaptation to an environment that includes coastal floods. During the winter months, cabana are evacuated because they are regularly flooded, sometimes multiple times a year. Still for the residents, this is part of how this place is, and they pass the knowledge from generation to generation: "He [his son] knows very well that in the cabana, in winter, he takes a 'bath'. My grandson, he knows it too. I mean, afterwards, if my grandson has children, he will say: well in winter, there's no point in going there" (man, $65 \mathrm{y}$, PSLR). 
Locals also express awareness of the continuous efforts by local authorities to inform them about flood risks and prevention. However, they also express that this constant effort makes them downplay emergency information. Participants claim they 'know' their environment and cannot be surprised by it: "for a small thing everyone cries 'wolf' once, twice, 3 times, 10 times [...] And the day when there is really something serious, nobody will believe it [...] We, we know, are used to it. So, we are not surprised, we have never been surprised". (man, 60y, PSLR).

These emotional ties to the environment appear related to a greater curiosity for how the local environment works and thus might reinforce the local capacity to find suitable risk adaptation strategies. This finding illustrates how place attachment can be positively associated with risk perception (Bonaiuto, et al., 2016). On the other hand, this content also shows a negative association between place attachment and risk perception when local risk knowledge contributes to reinforcing feelings of control and self-sufficiency - 'here, we know' - described as an attenuating factor for risk perception and preparedness (Luís et al., 2016). In the following section we will illustrate how discourse about local risks can help resolve the paradox between local place attachment and risk perception (Meur-Ferec \& Guillou, 2020).

\section{Argumentative strategies contributing to risk attenuation}

In general, local inhabitants described their vulnerability to coastal risks in optimistic terms. These optimistic argumentative strategies were categorised as the following: social comparison (e.g. we are not as exposed as they are); risk comparison (what about this other, more important, risk?) and fatalism (it is all so overwhelmingly bad, what can we do?). These arguments are often employed to justify the scarcity of protective actions taken. We describe below how locals in PSLR and in Fréjus used these risk attenuating arguments. 
One of the most frequent attenuation strategies was 'social comparison'. This argumentative strategy allows the individual to differentiate themself from a group that they consider to be strongly exposed to floods. Participants in PSLR - who are just east of the Camargue Delta - claim that they are not as exposed as other places in Camargue: "I will be at 'Les Saintes' yes, that [coastal floods] would be worrying. A city like 'Les Saintes' is worrying, but not here (man, 50y, PSLR). Fréjus dwellers also claim that it is people in Camargue who should be concerned with marine submersion, not them. Other geographical locations from which participants differentiate their vulnerability to coastal floods include: the Netherlands, Pacific islands, Bangladesh. "It has nothing to do with the storms in Brittany, eh!" (man, 74y, Fréjus) was a common comment referring to the Xynthia storm as the example of what can be considered as a "real" coastal flood risk.

The next frequently observed strategy is the one we called 'risk comparison'. Here participants mentioned other important risks present on their territory to justify their lack of preparedness in relation to coastal floods. In both localities, river flood and runoff flood hazards were mentioned as being the real problem for inhabitants, justifying their lack of concern with coastal flood hazards. Particularly in PSLR this argumentative strategy was observed in relation to industrial risks - and more precisely chemical pollution. "There is still a controversy on the pollution around the Golf de Fos. We have often had problems with contaminated fish from the Rhône and cultures around, seashells too" (woman, 38y, PSLR).

Finally, participants also resorted to 'fatalism' to justify their lack of concern with coastal risks. This strategy consists of presenting the problem as so overwhelmingly big that the individuals or local powers lack the ability to make a difference. "[...] The inertia of nature is enormous. And even if you start running all the way to the bottom, you will never be able to catch up with everything you've done, all the crap you've done before and the countermeasures you've taken. It's too late” (man, 74y, Fréjus). 
The argumentative strategies mentioned above all seem to share a common point: they are identity protective strategies in the sense that they allow these groups to restore their emotional well-being by rationalising or denying risk exposure (Breakwell, 2001). According to Breakwell (2001) elements of hazard information that might threaten an individual's selfesteem, efficacy, continuity, and distinctiveness, are likely to be 'adapted' before they integrate local representations of a risk: "the content and usage of a social representation (or mental model) can be predicted in relation to its likely impact upon the demands of individual identity requirements (Breakwell, 2001, p. 345). These argumentative strategies allow individuals to defend their chosen adaptation strategies by depicting coastal risks as either not as bad as other risks (social comparison and risk comparison), or so overwhelmingly bad coastal communities cannot do anything about them (fatalism). The identity protective role (Breakwell, 2001) played by these discursive strategies have here been presented as part of the intersubjective dynamics at play in social representations as a process, a point to which we will return to in the discussion. These shared emotion regulation strategies are part of how risks are understood by individuals with common bonds to groups and cultures (Joffe, 2003; Breakwell, 2001); they are part of what triggers collective meaning making in the first place (Joffe, 1999), even if emotions have been an under-analysed aspect of how societies attribute new meanings.

\section{Role of past risk events in risk amplification}

When participants discussed previous local catastrophes, the argumentative strategies they used to talk about these same risks was profoundly changed. Consistent with the gravity of past flood situations participants adopted a solemn tone to talk about risks and how we should take them seriously. "The dam failed in the wrong place. Water infiltrated under the bridge ... Vroum! [...] And the breach, in the time needed to react all northern Arles was flooded. I remember the pictures and everything” (man, 63y, PSLR). Both cities have recent river flood 
hazard events that profoundly marked citizens. Most participants in PSLR mention the Arles flood of 2003. Fréjus dwellers mentioned two events: the Malpasset dam failure over the Reyran river that heavily touched Fréjus in 1959; and a more recent flooding in 2010.

These events are described by inhabitants in great detail. These accounts of past disasters give an account about how river flood and runoff risks have been amplified since: they are engrained in the local shared memory and have changed the way these risks are managed at different institutional levels.

Still, in both cities, no memory exists of any disaster concerning coastal floods. Even if minor coastal flood events are reported frequently - i.e. cabana flooding every year in PSLR these events are more associated with regular natural rhythms to which people are adapted than with hazards that might require management and protective actions.

When participants discussed these past major events, they often argued, through what can be considered a meta-cognition, that local inhabitants and local administration respond to - but rarely anticipate - natural catastrophes. According to local dwellers, although they are exposed to coastal risks it is not until something 'big' impresses the mind that society or its representatives will respond to it. These risks are a technical abstraction, an invisible possibility until a catastrophe happens to make it real. "There really should be a big disaster. There should be a volcano that ... whose existence we don't know (laughter)" (woman, 80y, Fréjus). Another person explains that risk management tends to be responsive and will hardly propose risk preventive measures "uh, apart from the pump they put in place, I don't know. I think that at the political level, we need something to happen so that they move, instead of moving after something happens" (man, 60y, PSLR).

In these interviews, inhabitants demonstrate a clear-sightedness about the risk amplification process as described by SARF. They make an institutional observation based on past experiences leading to collective risk adaptation to river floods - something they have not 
yet observed in relation to coastal risks. These past catastrophic events resulted in authorities being held to account (Burgess, 2012), which has not yet been the case in relation to relatively minor coastal events experienced on the Mediterranean French coast.

Participants' observations of institutional lack of pre-emptive action may reinforce the argumentative strategies resulting in risk attenuation (see last section) by contributing to general apathy about risk and adaptation.

\section{Discussion}

As coastal floods and events are expected to grow stronger and become more frequent due to climate change, it becomes crucial to understand how communities already exposed to these risks make sense of and prepare for these evolving risks. We have described the argumentative strategies used by inhabitants of two cities in southern France to describe how they understand and prepare for coastal risks. Considering that finding meaning that is particular to each of the studied communities was central to this endeavour, we opted for a constructivist approach - the social representations theory (Moscovici, 2001) - combined with a longitudinal frame for risk analysis - social amplification of risk framework (Kasperson et al., 2003).

Results were organised around (1) a risk knowledge category, named 'knowledge of coastal flood risk exposure' and (2) personal and local history designated as 'emotional ties to the coast'. Two further categories group argumentative strategies that demonstrate how social representational processes contribute to risk amplification and risk attenuation: (3) 'risk relativization (risk attenuation)' and (4) 'role of past risk events (risk amplification)'.

(1) Regarding coastal risk knowledge we highlighted that problems associated with river floods or heightened run-off occupy an important place in local discourse about coastal flooding. This reference to a related source of risk (river) can be understood as a collective effort to deal with coastal risks and to make them 
concrete. Given that a major coastal flood event has not been experienced in these localities, river flood is invoked instead - which might share some characteristics but is characterised and managed differently. The two dangers correspond to distinct categories in the local flood risk prevention plan (PPRI). Participants also made abundant use of expert concepts in their references to the coast, dikes and the hydrodynamics that rule the region (similarly to findings of French Atlantic coastal studies; Meur-Ferec \& Guillou, 2020).

(2) Coastal communities share a specific relation to their territory, marked by maritime culture and the strong attraction of the seaside in recent decades. More precisely, PSLR dwellers are geographically isolated and surrounded by salt marshes - creating their strong insular identity and strong community and environmental ties. The cabana is here described as a bridge between the community's social space and the natural environment, an environment that is described as a part of themselves. Risk associated with the coastal floods that hit the coast every winter is therefore described as part of nature, a nature they respect and feel well adjusted to. Fréjus inhabitants praise the beauties of their coast which motivated a good number of them to move there. Yet due to the lack of a major coastal flood event in both PSLR and Fréjus, study participants hesitate to formulate how they could be affected by coastal floods in their lifetime. This analysis illustrates the paradox described by Meur-Ferec and Guillou (2020) in which individuals remain attached to the coast, despite knowing the dangers to which they are exposed.

(3) Individuals compensate such inconsistency through rationalisations (Breakwell, 2001) that allow coastal dwellers to continue enjoying the pleasures of life by the sea. These rationalisations were identified in the form of argumentative strategies: social comparison, risk comparison and fatalism. These strategies allow 
individuals to relativize the risk and then justify both the individual and collective apathy regarding the absence of protective actions. Together the resort to these types of argumentative strategies contributes to social attenuation (Kasperson, et al., 2003) of coastal flood risks.

(4) This collective effort to attenuate the coastal flood risk would come to an end, in the participants' analysis, the day where 'something' happens. According to them, the fact that no social memory is yet available regarding coastal risks contributes to political inertia and, consequently, to the citizens' passivity regarding this risk. Literature has shown for example that human casualties are an important ingredient in the search for accountability and change in risk preparedness - e.g. the Xynthia storm in France (Lelaurain et al., in press).

Interviewees are therefore aware of the power catastrophes have in moving the lines of how risks are managed when they analyse that 'something must happen' for these risks to be taken seriously. This something we interpret as a need for an event capable of objectifying these still abstract risk ideas which can then be associated with metaphors or symbols, making them more clearly identifiable and easily communicated (Moscovici, 1984). We propose that unless a risk is 'objectified' through a collective experience - e.g. a catastrophe that makes the headlines it continues to be opaque and resistant to individual and collective response. It is the collective experience of social amplification that can add new images about natural phenomena to the symbolic tissue and galvanize social response around it, a process Moscovici (2001) described as objectification.

The four points described above illustrate how the communities of Fréjus and PSLR have previous experiences with fluvial floods, are attached to their local coastal environment, and attenuate the risk associated with coastal floods through a variety of argumentative strategies. Where these two communities differ is in how they attenuate the occurrence of coastal risks. In 
PSLR, local inhabitants downplay their potential exposure to coastal floods by framing these as a phenomenon that is limited to the region of the Rhône Delta where the cabanas are located. Here, coastal floods are seen as a part of how these communities live with and respect the natural environment. In Fréjus, participants relativize their exposure to coastal episodes by mentioning the other natural hazards that hit their territory - e.g. river floods, run-off, forest fires. They also frequently resort to the social comparison argumentative strategy and state that coastal floods are a problem especially for the Camargue - where PSLR is situated.

A similarity between the two cities is found in regard to how participants expect the environment to evolve with a changing climate. Here, fatalist argumentative strategies are used to justify their lack of action: that the situation is too bad for them to make a difference; they will be long gone. Overall, the qualitative analysis shows a similar psychosocial paradox identified in the French Atlantic coast (Meur-Ferec \& Guillou, 2020) and here: a strong attachment to the coast is accompanied by risk rationalisation. These rationalisations might take different forms (e.g. risk relativization, group relativization, fatalism) but the goal is still to support “individual's self-esteem, efficacy, continuity and distinctiveness” (Breakwell, 2001, p. 349).

This interpretation about how socially shared representations respond to individual concerns with identity preservation opens the discussion of another point that is central for our analysis: what are discursive strategies in relation to social representations? If we approach social representations theory as a phenomenon and not as a concept (Moscovici, 1984) we must conceive them as part of dynamic contexts where social groups and individuals communicate, cooperate, agree, and disagree. Therefore, a richer description of how social representations are used involves, more than a description of the self-other communicative contexts, the practical consequences of a discourse within a specific self-other context (Castro \& Batel, 2018). By analysing argumentative strategies in the context of social representations we are able to 
"understand why those discourses are, specifically, and what are their different appropriations being used for - persuasion? discrimination? coping with change? resisting it?" (Castro \& Batel, 2018, p. 16). This study has attempted to describe these argumentative strategies as a shared psychosocial strategy to cope - at the present - with the inevitable future adaptations inhabitants will have to make in relation to the consequences of climate change in their territory.

The data presented and discussed above have described how the rationalisation of coastal risks happens in two very precise locations. Yet this analysis supports a broader reflection about how we, as individuals and as societies, deny and fail to prepare for hazards we have not directly experienced as a society. Rationalising as a coping mechanism has been demonstrated by the literature in relation to different types of natural or industrial risks. This does not mean that societies with all the institutional apparatus to account for risk preparedness can afford to use the same heuristics as individuals use. Preparedness exercises for stakeholders can counter this type of rationalisation by organizing, for example, a more widespread use of local scenario workshops (Poumadère et al., 2015), or virtual reality exercises to render more concrete the representation of abstract risks for which a collective memory has not yet been created.

\section{References}

Bourrelier, P.-H., Deneufbourg, G., \& de Vanssay, B. (2000). Les catastrophes naturelles: Le grand cafouillage [Natural disasters: The big mess]. Paris: Osman Eyrolles Santé \& Société.

IPCC (2007). Climate Change 2007: Synthesis Report. Contribution of Working Groups I, II and III to the Fourth Assessment Report of the Intergovernmental Panel on Climate Change [Core Writing Team, Pachauri, R.K and Reisinger, A. (eds.)]. Geneva, IPCC.

Serra-Llobet, A., David Tàbara, J., \& Sauri, D. (2013). The Tous dam disaster of 1982 and the origins of integrated flood risk management in Spain. Natural Hazards, 65, 1981-1998. https://doi.org/10.1007/s11069-012-0458-0

Wagner, W., \& Hayes, N. (2005). Everyday discourse and common sense. The theory of social representations. Basingstoke, UK: Palgrave Macmillan. 
Bakir, V. (2005). Greenpeace v. Shell: Media exploitation and the Social Amplification of Risk Framework (SARF). Journal of Risk Research, 8(7-8), 679-691. https://doi.org/10.1080/13669870500166898

Batel, S., \& Castro, P. (2018). Reopening the dialogue between the theory of social representations and discursive psychology for examining the construction and transformation of meaning in discourse and communication. British Journal of Social Psychology, 57(4), 732-753. https://doi.org/10.1111/bjso.12259

Bauer, M. W., \& Gaskell, G. (2008). Social representations: A progressive research programme for social psychology. Journal for the Theory of Social Behaviour, 29, 163186. https://doi.org/10.1111/j.1468-5914.2008.00374.x

Bertoldo, R., Tanga, R., Dias, P., Guignard, S., \& Schleyer-Lindenmann, A. (2020). Calculative and relational trust in the management of coastal floods and earthquakes: a comparative study. PsyEcology, 11(2), 193-213. https://doi.org/10.1080/21711976.2020.1734398

Bonaiuto, M., Alves, S., De Dominicis, S., \& Petruccelli, I. (2016). Place attachment and natural environmental risk: Research review and agenda. Journal of Environmental Psychology, 48(2016), 33-53. https://doi.org/10.1016/j.jenvp.2016.07.007

Bourrelier, P.-H., de Vanssay, B., \& Deneufbourg, G. (2000). Evaluation de la politique publique de prévention des risques naturels : résumé du rapport [Assessment of the public policy for the prevention of natural risks: Summary of the report]. In. : P.-H. Bourrelier, G. Deneufbourg, \& B. de Vanssay, Les catastrophes naturelles: Le grand cafouillage (pp. 155-210). Paris: Osman Eyrolles Santé \& Société.

Breakwell, G. M. (2001). Mental models and social representations of hazards: the significance of identity processes, 4(4), 341-351.

https://doi.org/10.1080/1366987011006273

Burgess, A. (2012). Media, risk, and absence of blame for "Acts of God": Attenuation of the European volcanic ash cloud of 2010. Risk Analysis, 32(10), 1693-1702. https://doi.org/10.1111/j.1539-6924.2012.01803.x

Calvet, F. \& Manable, C. (2015). Xynthia 5 ans après: Pour une véritable culture du risque dans les territoires [Xynthia 5 years later: For a true culture of risk in the territories]. Rapport d'information n. 536, Sénat [French Senate]. Available at: https://www.senat.fr/rap/r14-536/r14-536_mono.html\#toc275

Castro, P., \& Batel, S. (2008). Social representation, change and resistance: On the difficulties of generalizing new norms. Culture \& Psychology, 14(4), 475-497. https://doi.org/10.1177/1354067X08096512

Chadenas, C., Creach, A., \& Mercier, D. (2014). The impact of storm Xynthia in 2010 on coastal flood prevention policy in France. Journal of Coastal Conservation, 18(5), 529538. https://doi.org/10.1007/s11852-013-0299-3

Cramer, W., Guiot, J., Fader, M., Garrabou, J., Gattuso, J.-P., Iglesias, A., Lange, M. A., Lionello, P., Llasat, M. C., Paz, S., Peñuelas, J., Snoussi, M., Toreti, A., Tsimplis, M. N., 
\& Xoplaki, E. (2018) Climate change and interconnected risks to sustainable development in the Mediterranean. Nature Climate Change 8, 972-980, doi: 10.1038/ s41558-018-0299-2

Delicado, A., Guerreiro, S., \& Gomes, C. (2012). Pescadores , conhecimento local e mudanças costeiras no litoral Português [Fishermen, local knowledge and coastal change on the Portuguese coastline]. Revista Da Gestão Costeira Integrada, 12(4), 437-451. https://doi.org/10.5894/rgci349

Doue, C. M., Carrascal, O. N., Restrepo, D., Krien, N., Rommel, D., Lemee, C., ... FleuryBahi, G. (2020). The social representations of climate change: comparison of two territories exposed to the coastal flooding risk. International Journal of Climate Change Strategies and Management, 12(3), 389-406. https://doi.org/10.1108/IJCCSM-11-20190064

Durand, P., Anselme, B., Defossez, S., Elineau, S., Gherardi, M., Goeldner-Gianella, L., ... Nicolae-Lerma, A. (2018). Coa)stal flood risk: improving operational response, a case study on the municipality. Geoenvironmental Disasters, 1, 1-17.

Flick, U. (2014). An introduction to qualitative research. London: Sage.

Freedman, A., Dennis, B., \& Karklis, L. (2020, June 29). Millions of homeowners face flood risks without realizing it, and climate change is making it worse. The Washington Post. Available at: https://www.washingtonpost.com/weather/2020/06/29/flood-risk-climatechange/

Harré, R. (1998). The epistemology of social representations. In U. Flick (Ed.), The psychology of the social (pp. 129-137). Cambridge, England: Cambridge University Press.

Hayes, A. F., \& Krippendorff, K. (2007). Answering the call for a standard reliability measure for coding data. Communication Methods and Measures, 1(1), 77-89.

IPCC (2018). Global Warming of $1.5^{\circ} \mathrm{C}$. An IPCC Special Report on the impacts of global warming of $1.5^{\circ} \mathrm{C}$ above pre-industrial levels and related global greenhouse gas emission pathways, in the context of strengthening the global response to the threat of climate change, sustainable development, and efforts to eradicate poverty [Masson-Delmotte, V., P. Zhai, H.-O. Pörtner, D. Roberts, J. Skea, P.R. Shukla, A. Pirani, W. Moufouma-Okia, C. Péan, R. Pidcock, S. Connors, J.B.R. Matthews, Y. Chen, X. Zhou, M.I. Gomis, E. Lonnoy, T. Maycock, M. Tignor, and T. Waterfield (eds.)]. In Press.

Ivcevic, A., Bertoldo, R., Mazurek, H., Siame, L., Guignard, S., Ben Moussa, A., \& Bellier, O. (2020). Local risk awareness and precautionary behaviour in a multi-hazard region of North Morocco. International Journal of Disaster Risk Reduction, 50. https://doi.org/10.1016/j.ijdrr.2020.101724

Joffe, H. (1999). Risk and the other. Cambridge: Cambridge University Press.

Joffe, H. (2003). Risk: From perception to social representation. British Journal of Social Psychology, 42, 55-73. 
Kasperson, J. X., Kasperson, R. E., Pidgeon, N., \& Slovic, P. (2003). The social amplification of risk: Assessing fifteen years of research and theory. In N. Pidgeon, R. E. Kasperson \& P. Slovic (Eds.), The social amplification of risk (pp. 13-79). Cambridge: Cambridge University Press.

Kasperson, R. E., Renn, O., Slovic, P., Brown, H. S., Emel, J., Goble, R., ... Ratick, S. (1988). The Social Amplification of Risk: A conceptual framework. Risk Analysis, 8(2), 177-187.

Krien, N., \& Michel-Guillou, E. (2014). Place des risques côtiers dans les représentations sociales du cadre de vie d'habitants de communes littorales. Les Cahiers Internationaux de Psychologie Sociale, 101(101-122).

Lelaurain, S., Guignard, S., Schleyer-Lindenmann, A. \& Bertoldo, R. (2021). From risk to legislative innovation: The trajectory of marine submersion through the French media. Environmental Communication, https://doi.org/10.1080/17524032.2021.1954538

Lewins, A., \& Silver, C. (2007). Using software in qualitative research: A step-by-step guide. London: Sage.

Luhmann, N. (1979). Trust and power: Two works. Chichester: John Wiley.

Luís, S., Pinho, L., Lima, M. L., Roseta-Palma, C., Martins, F. C., \& Betâmio de Almeida, A. (2016). Is it all about awareness? The normalization of coastal risk. Journal of Risk Research, 19(6), 810-826. https://doi.org/10.1080/13669877.2015.1042507

Meur-Ferec, C. \& Guillou, E. (2020). Interest of Social Representations Theory to grasp coastal vulnerability and to enhance coastal risk management. PsyEcology, 11(1), 78-89. https://doi.org/10.1080/21711976.2019.1644003

Michel-Guillou, E., \& Meur-Ferec, C. (2017). Representations of coastal risk (erosion and marine flooding) among inhabitants of at-risk municipalities. Journal of Risk Research, 20(6), 776-799. https://doi.org/10.1080/13669877.2015.1119181

Michel-Guillou, E., Krien, N., \& Meur-Ferec, C. (2016). Inhabitants of coastal municipalities facing coastal risks: Understanding the desire to stay. Papers on Social Representations, 25(1), 8.1-8.21.

Michel-Guillou, E., Lalanne, P.-A., \& Krien, N. (2015). Hommes et aléas: Appréhension des risques côtiers par des usagers et des gestionnaires de communes littorales [People and hazards: Understanding of coastal risks by users and managers of coastal municipalities]. Pratiques Psychologiques, 21(1), 35-53. https://doi.org/10.1016/j.prps.2014.12.001

Moscovici, S. (1976). La psychanalyse, son image et son public [The psychoanalysis, its image and its public]. Paris: Presses Universitaires de France.

Moscovici, S. (1984). The phenomenon of social representations. In R. Farr \& S. Moscovici (Eds.), Social representations (pp. 3-69). Cambridge University Press.

Moscovici, S. (2001). Why a theory of social representations? In K. Deaux \& G. Philogene (Eds.), Representations of the social (pp. 8-35). Oxford: Blackwell. 
Nazarea, V. D. (2006). Local Knowledge and memory in biodiversity conservation. Annual Review of Anthropology, 35, 317-35.

https://doi.org/10.1146/annurev.anthro.35.081705.123252

Pidgeon, N., Kasperson, R. E., \& Slovic, P. (2003) Social Amplification of Risk. Cambridge: Cambridge University Press.

Poumadère, M., Bertoldo, R., Idier, D., Mallet, C., Oliveros, C., \& Robin, M. (2015). Coastal vulnerabilities under the deliberation of stakeholders: The case of two French sandy beaches. Ocean \& Coastal Management, 105, 166-176. https://doi.org/10.1016/j.ocecoaman.2014.12.024

Renn, O. (2008). Risk governance: Coping with uncertainty in a complex world. London: Earthscan.

Slovic, P. (2000). The perception of risk. London: Earthscan.

Smith, J. A. (1995). Semi-structured interviewing and qualitative analysis. In.: J. A. Smith, R. Harré, \& L. Van Langenhove, L., Rethinking methods in psychology (pp. 9-26). London: Sage.

Wynne, B. (1996). May the sheep safely graze? A reflexive view of the expert-lay knowledge divide. In S. Lash, B. Szerszynski, \& B. Wynne (Eds.), Risk Environment and Modernity: Towards a New Ecology (pp. 44-83). London: Sage. 


\section{Acknowledgements}

This work is a contribution to Labex OT-Med ( ${ }^{\circ}$ ANR-11-LABX-0061) and received funding from Excellence Initiative of Aix-Marseille University-A*MIDEX, a French “Investissements d'Avenir" programme (RISKMED project). Additional funding was provided for the study in France by the European Union-FEDER programme (DIGUE 2020 project). We would also like to thank Claire Mays for carefully reviewing a first version of this manuscript. 